Received: $\quad 2019.03 .08$

Accepted: 2019.03.25

Published: 2019.08 .12

\title{
Pancratistatin Inhibits the Growth of Colorectal Cancer Cells by Inducing Apoptosis, Autophagy, and G2/M Cell Cycle Arrest
}

Authors' Contribution: Study Design A Data Collection B Statistical Analysis C Data Interpretation D Manuscript Preparation E Literature Search F Funds Collection G
ABCDEF 1 Yong Xiong

BCDEF 2 Yi-Jia Xiong

BCDEF 1 Dong-Yang Liu

ABCDEFG 1 Rong-Rong Shen
1 Department of General Surgery, Shanghai Sixth Peoples' Hospital East Affiliated to Shanghai University of Medicine and Health Sciences, Shanghai, P.R. China 2 Department of Radiology, Shanghai Sixth Peoples' Hospital, Shanghai, P.R. China
Corresponding Author: Source of support:
Rong-Rong Shen, e-mail: RichieWattsfdv@yahoo.com Departmental sources

Background: Worldwide, colorectal cancer is ranked as the third most prevalent cancer. The natural compound, pancratistatin, extracted from the spider lily, has previously been shown to target apoptosis in cancer cells lines. This study aimed to investigate the effects of pancratistatin in human colorectal cancer cells in vitro.

Material/Methods: Human colorectal cancer cell lines, including HTC-15 cells, were compared with a normal human colonic fibroblast cell line, CDD-18Co. Cells were treated with increasing doses of pancratistatin. The MTT assay was used to assess cell viability. Fluorescence microscopy using DAPI and Annexin-V/propidium iodide (PI) was used to detect cell apoptosis. Cell autophagy was detected by electron microscopy. Cell migration was evaluated using a wound healing assay, and Western blot determined the expression levels of cell cycle proteins.

Results: Pancratistatin inhibited the growth of the colorectal cancer cells with an $\mathrm{IC}_{50}$ ranging from 15-25 $\mu \mathrm{M}$, but had a limited effect in normal CCD-18Co cells, with an $\mathrm{IC}_{50}$ of $>100 \mu \mathrm{M}$. Pancratistatin reduced HCT-15 cell migration. Growth inhibition due to pancratistatin was associated with morphological changes of HCT-15 cells and included autophagy and apoptosis, and increased expression the autophagic proteins, LC3II, beclin-1, and Bax. Pancratistatin induced arrest of HCT-15 cells at G2/M of the cell cycle and inhibited phosphorylation of cdc2/cyclin-dependent kinase 1 (CDK1) and Cdc25c and the expression of cyclin B1.

Conclusions: $\quad$ Pancratistatin inhibited the growth of colorectal cancer cells in vitro by inducing apoptosis, autophagy, and G2/M cell cycle arrest.

MeSH Keywords:

Apoptosis • Autophagy • Cell Cycle

Full-text PDF: https://www.medscimonit.com/abstract/index/idArt/916116

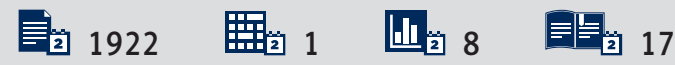




\section{Background}

Worldwide, colorectal cancer is ranked as the third most common type of cancer and the fourth major cause of cancer-related death and results in a large health and economic burden, with 1.4 million cases of colorectal cancer cases reported annually [1]. In 2013, around 0.7 million deaths were reported to be due to colorectal cancer throughout the world [2]. Although the incidence of colorectal cancer has declined to some extent, it has been predicted that the incidence of colorectal cancer will increase by $60 \%$ in the year 2030 [3]. Late diagnosis and the lack of safe and effective chemotherapy remain obstacles in the treatment of colorectal cancer [4]. Recently, the use of active compounds extracted from natural herbal medicines has gained increased attention for the treatment of human disease [5]. There have been increasing numbers of studies that have investigated the pharmacological effects of ayurvedic or alternative medicines.

Many chemically synthesized drugs are derivatives of drugs derived from plants and herbs [5]. Medicinal plants or extracts have been used as adjuvant or alternative therapies in certain parts of the world, including in China, and are preferred due to their reduced toxicity, low cost, and local availability [6]. Although herbal medicines have been used for many centuries, the use of pure isolated compounds from herbal medicines have been used and investigated since the $19^{\text {th }}$ century, and a wide range of molecules have now been isolated, evaluated and used for the treatment human diseases [7]. The natural compound, pancratistatin, extracted from the spider lily or amaryllidaceae family of angiosperms, has previously been shown to target apoptosis in cancer cell lines [8]. Pancratistatin is a pharmacologically important compound and a wide array of pharmacological properties have been attributed to it, including its anticancer properties [9]. Pancratistatin has been shown to inhibit the growth of several malignant cell lines, including human lymphoma cells [10]. However, the anticancer effects of pancratistatin have not been extensively studies in colorectal cancer cell lines. Therefore, this study aimed to investigate the effects of pancratistatin in human colorectal cancer cells in vitro.

\section{Material and Methods}

\section{Cell lines and cell culture conditions}

The human colorectal cancer cell lines HT-29, SW948, DLD-1, and HTC-15 and the normal colonic fibroblast cell line, CDD$18 \mathrm{Co}$, were purchased from the Cancer Research Institute of Beijing, China. The cell lines were cultured in Dulbecco's modified Eagle's medium (DMEM) containing 10\% fetal bovine serum (FBS), $100 \mu \mathrm{g} / \mathrm{ml}$ of streptomycin, and $100 \mathrm{U} / \mathrm{ml}$ of penicillin $\mathrm{G}$.

\section{Cell viability}

The HCT-15 human colorectal cancer cells were cultured and treated with pancratistatin (98\% pure) (Toronto Research Chemicals, North York, ON, Canada) at increasing concentrations, from $0-200 \mu \mathrm{M}$ for $24 \mathrm{~h}$ at $37^{\circ} \mathrm{C}$. The cells were then treated with 3-(4,5-dimethylthiazol-2-yl)-2,5-diphenyltetrazolium bromide (MTT) $(500 \mu \mathrm{g} / \mathrm{mL})$ for $4 \mathrm{~h}$. Dimethyl sulfoxide (DMSO) (10\%) was added to dissolve the blue formazan formed. Finally, cell viability at an optical density (OD) of $570 \mathrm{~nm}$ was measured using a spectrophotometer (BD Biosciences, San Jose, CA, USA).

\section{4',6-diamidino-2-phenylindole (DAPI) staining assay}

HCT-15 cells $\left(0.6 \times 10^{6}\right)$ were cultured in six-well plates and treated with pancratistatin at increasing concentrations of 0 , $7.5,15$, and $30 \mu \mathrm{M}$ for $24 \mathrm{hr}$ at $37^{\circ} \mathrm{C}$. Then, $25 \mu \mathrm{l}$ of cultured cells were placed onto glass slides and stained with DAPI. The slides were then coverslipped and examined by fluorescence microscopy (BD Biosciences, San Jose, CA, USA).

\section{Annexin-V/fluorescein isothiocyanate (FITC) and Annexin-V/propidium iodide (PI) staining assay}

The ApoScan Annexin-V/FITC and Annexin-V/PI apoptosis detection kit (BioBud, Gyeonggi-Do, Korea) were used to measure the proportion of apoptotic HCT-15 cells. Briefly, pancratistatintreated HCT- 15 cells $\left(5 \times 10^{5}\right.$ cells per well) were incubated for $24 \mathrm{~h}$ at $37^{\circ} \mathrm{C}$, followed by the staining with Annexin-V/FITC or Annexin-V/PI. The percentage of apoptotic HCT-15 cells with each concentration of pancratistatin was then determined by flow cytometry (BD Biosciences, San Jose, CA, USA).

\section{Electron microscopy}

The induction of autophagy in pancratistatin-treated colorectal cancer cells was assessed by electron microscopy. Briefly, the colorectal HCT-15 cancer cells were treated with $0,7.5,15$, and $30 \mu \mathrm{M}$ of pancratistatin for $24 \mathrm{~h}$. The cells were collected by trypsinization, washed, and fixed in $2 \%$ glutaraldehyde in phosphate buffered saline (PBS) $(0.1 \mathrm{M})$. The cells were then post-fixed in $1 \%$ osmium tetroxide, followed by treatment of the cells with ethanol and embedding in resin. The thin sections were then cut using an ultramicrotome and were examined by electron microscopy.

\section{Wound healing assay}

After treatment of the HCT-15 cells with pancratistatin, the culture medium was removed and the cells were washed in PBS. A sterile pipette tip was used to scratch a wound in each well, the cells were washed again and the results were photographed. 
The cells were cultured for a further $24 \mathrm{~h}$ and photographed again using an inverted microscope (Leica, Wetzlar, Germany).

\section{Western blot}

The HCT-15 cells were lysed in lysis buffer containing protease inhibitor. Around $45 \mu \mathrm{g}$ of protein from each sample was diluted to $10 \%$ and transferred to polyvinylidene difluoride (PVDF) membranes. Dried skimmed milk powder was used to block the membranes at room temperature for $1 \mathrm{~h}$. The membranes were treated with primary antibodies at $4^{\circ} \mathrm{C}$ overnight. The membranes were incubated with secondary antibodies, and the signal was detected using the Odyssey CLx Near-Infrared Fluorescence Imaging System (LI-COR Biosciences, Lincoln, NE, USA). Actin was used as the control.

\section{Statistical analysis}

All the experimental procedures were performed in triplicate. The values for the data were presented as the mean of three replicates \pm the standard deviation (SD). $\mathrm{P}<0.05$ and $\mathrm{P}<0.01$ were considered to be statistically significant. The statistical analysis was performed Student's t-test and using GraphPad Prism version 7 software (GraphPad Software, La Jolla, CA, USA).
Table 1. Antiproliferative effects of pancratistatin on the colorectal cancer cells and the normal cell line (CDD18Co) determined by the MTT assay and expressed as $\mathrm{IC}_{50}$ values.

\begin{tabular}{|ccc|}
\hline S. No & Cell line & IC $_{\mathbf{5 0}}(\boldsymbol{\mu M})$ \\
\hline 1 & HT-29 & 25 \\
\hline 2 & HCT-15 & 15 \\
\hline 3 & SW948 & 20 \\
\hline 4 & DLD-1 & 25 \\
\hline 5 & CDD-18Co & $>100$ \\
\hline
\end{tabular}

\section{Results}

\section{Pancratistatin reduced the viability of HCT-15 colorectal cancer cells}

The MTT assay was used to assess the effects of pancratistatin on the viability of the human colorectal cancer cell lines HT-29, SW948, DLD-1, and HTC-15 and the normal colonic fibroblast cell line, CDD-18Co. Although pancratistatin inhibited the growth of all cancer cell lines, a greater effect was observed on the proliferation of HCT-15 cells, with an $\mathrm{IC}_{50}$ of $15 \mu \mathrm{M}$ (Table 1). The effects of pancratistatin on the viability of the HCT-15 cells were concentration-dependent with an $\mathrm{IC}_{50}$

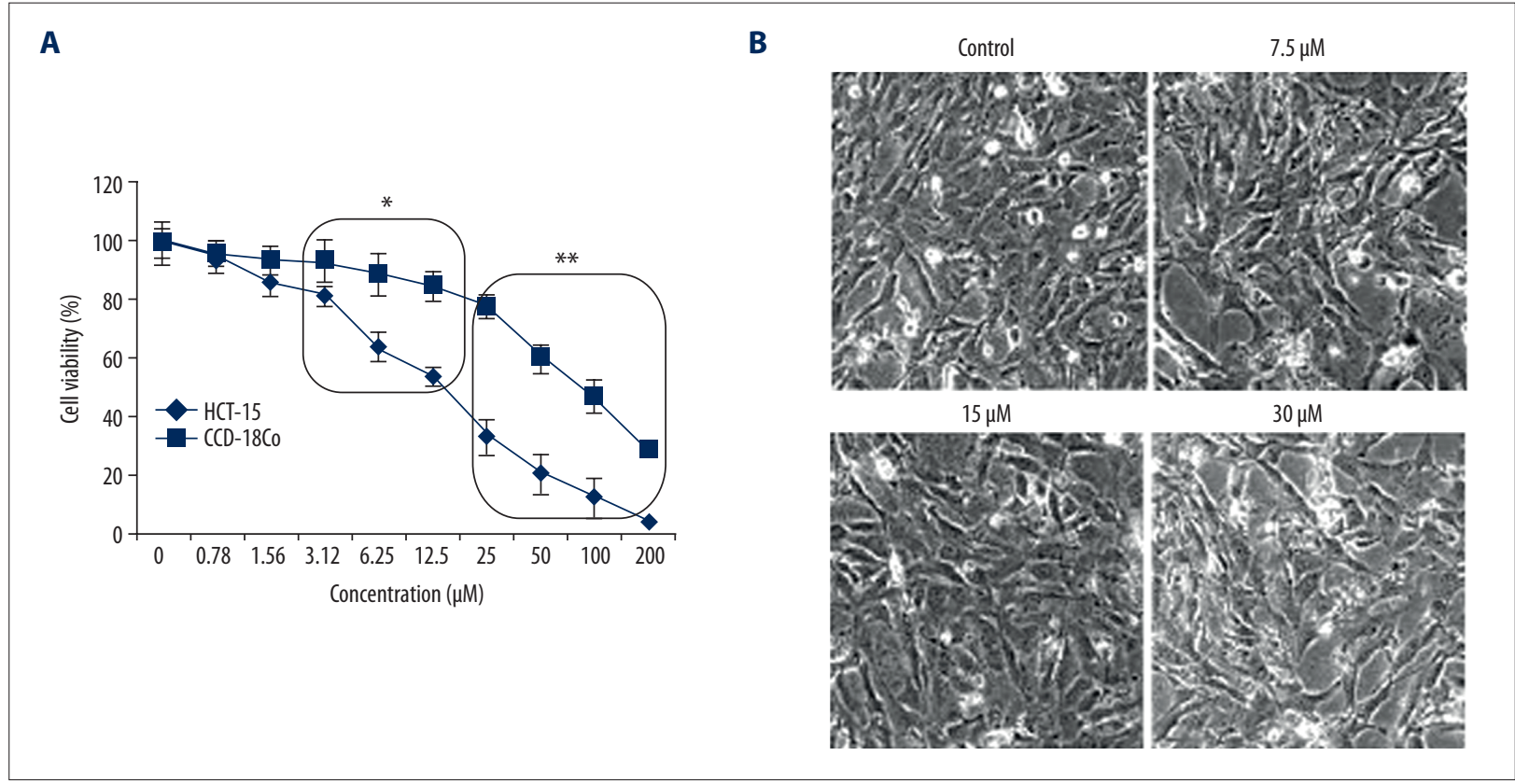

Figure 1. The effects of pancratistatin on cell viability and cell morphology of HCT-15 colorectal cancer cells in vitro. (A) MTT cell viability assay shows the dose-dependent growth inhibitory effects of pancratistatin on HCT-15 colorectal cancer cells and normal CCD-18Co cells. (B) Histology of HCT-5 cells shows that pancratistatin induced morphological changes. The experiments were performed in triplicate, and the results are expressed as the mean \pm standard deviation (SD) ( ${ }^{*}<0.05$ for the colorectal cancer cell line compared with the normal cell line). 


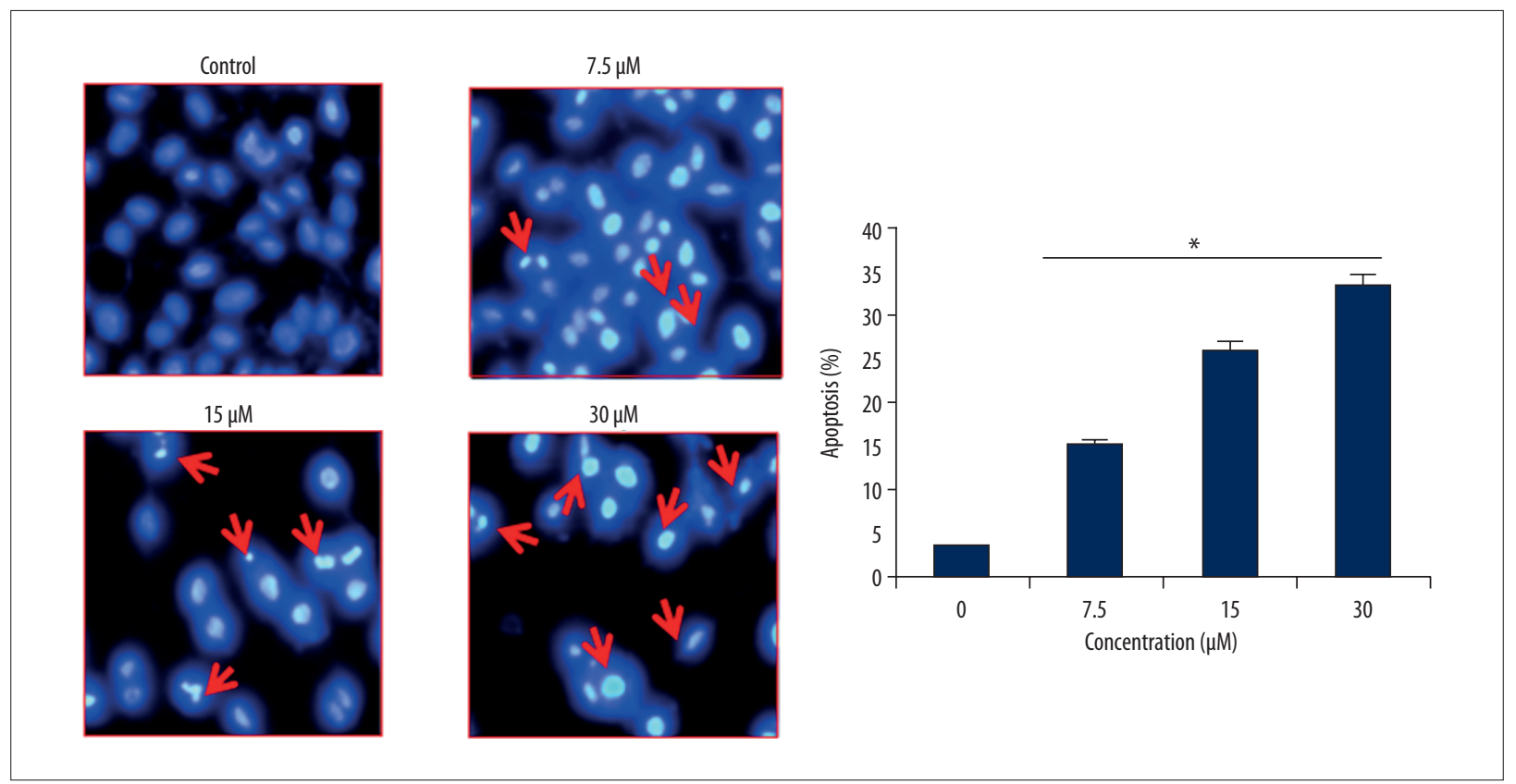

Figure 2. DAPI staining shows nuclear fragmentation induced by pancratistatin in HCT-15 cells at the indicated concentrations, suggestive of autophagy. The experiments were performed in triplicate (the arrows show the apoptotic cells).

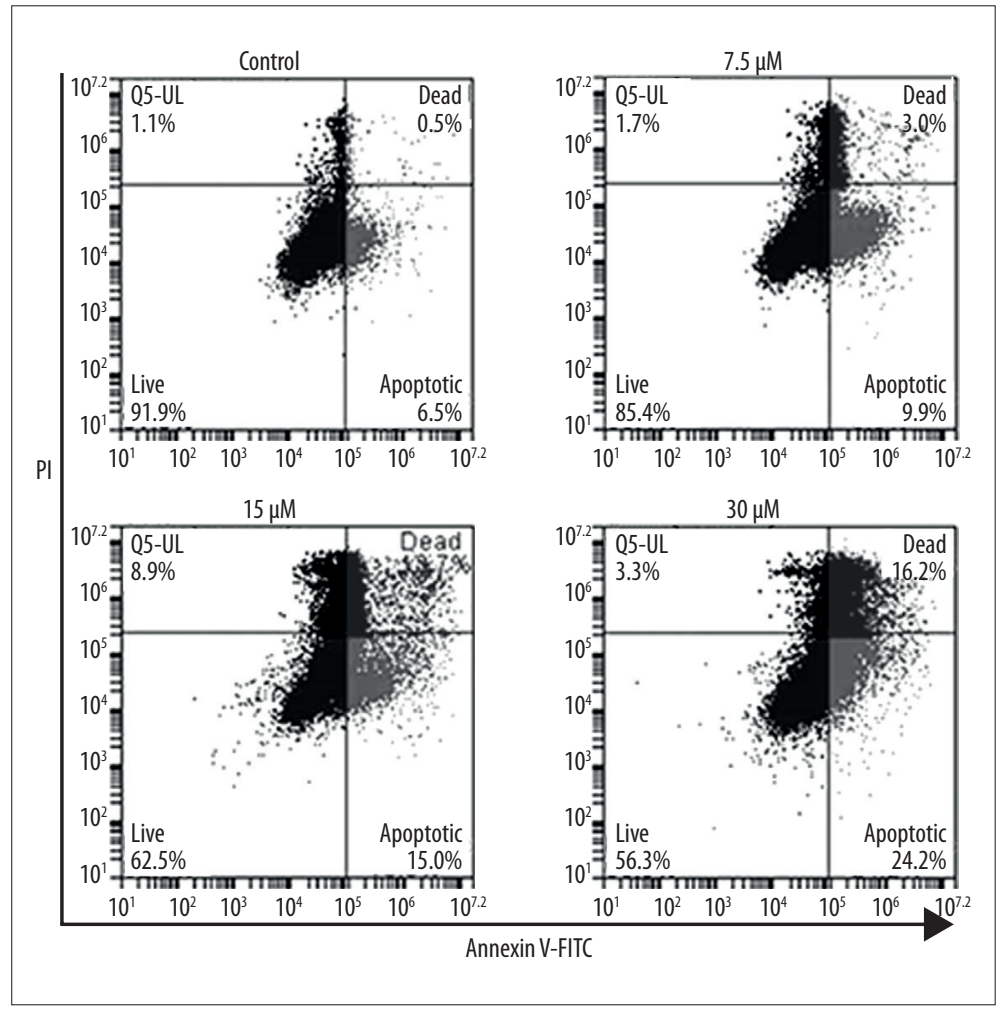

Figure 3. Annexin-V/propidium iodide (PI) staining shows the percentage of the apoptotic HCT-15 cells at indicated concentrations of pancratistatin. The experiments were performed in triplicate.

of $15 \mu \mathrm{M}$ for pancratistatin treatment (Figure $1 \mathrm{~A}$ ). The effects of pancratistatin on the normal CDD-18Co cells were less apparent, with an IC50 of >100 (Figure 1A). Light microscopy was used to evaluate the effects of pancratistatin on the morphology of HCT-15 cells and showed that pancratistatin treatment was associated with significant changes in the morphology of the HCT-15 cells that included cell rounding, membrane blebbing, and shrinkage (Figure 1B). 


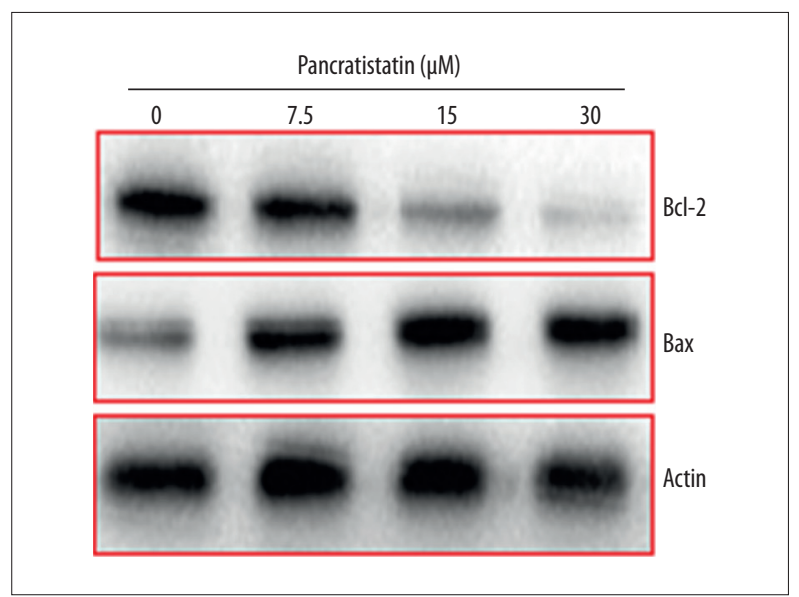

Figure 4. Western blot shows that pancratistatin resulted in increased expression of Bax and reduced expression of $\mathrm{Bcl}-2$. The experiments were performed in triplicate.

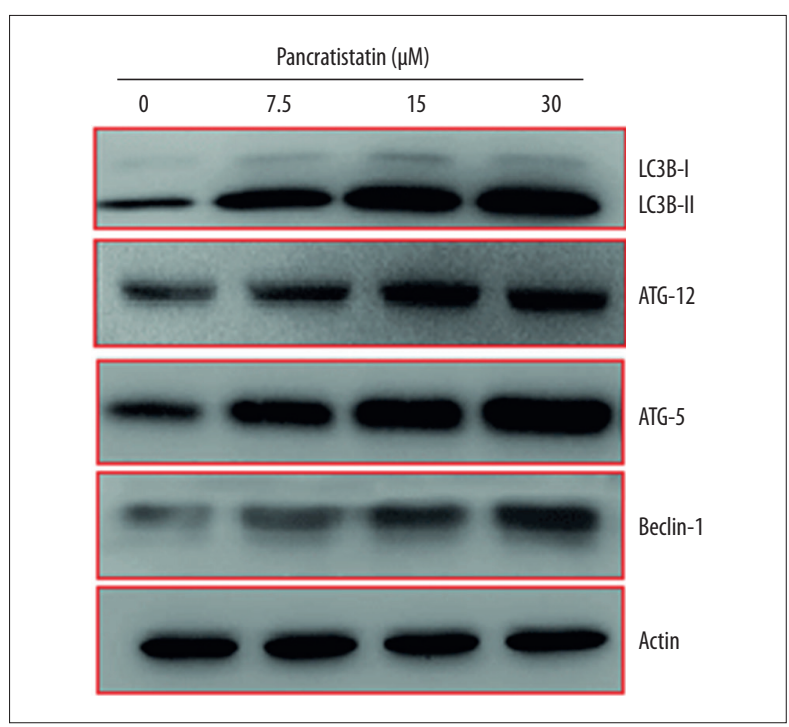

Figure 6. Western blot shows that pancratistatin treatment resulted in a dose-dependent increase in the expression of LC3 II, ATG-12, ATG-5, and beclin-1. The arrows indicate the autophagosomes. The experiments were performed in triplicate.

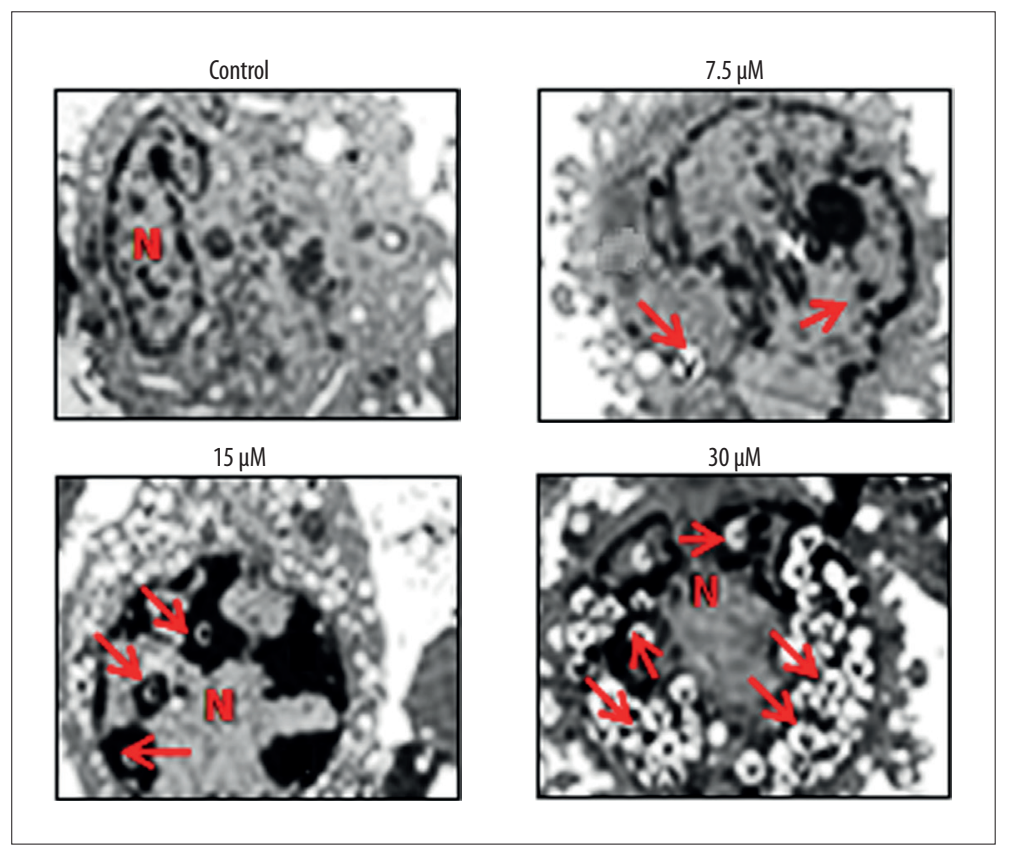

Figure 5. Electron microscopy shows that pancratistatin induced autophagy in the HCT-15 cells. The arrows indicate the autophagosomes. The experiments were performed in triplicate.

\section{Pancratistatin treatment induced apoptosis in colorectal cancer cells}

To determine the underlying mechanism for the growth inhibitory properties of pancratistatin, the HCT-15 cells were treated with different doses of pancratistatin and then stained with DAPI. The fluorescence results of the DAPI assay showed that pancratistatin caused nuclear fragmentation of the HCT-15 cells, which was characteristic of apoptosis (Figure 2).
Annexin- $\mathrm{V} /$ propidium iodide $(\mathrm{PI})$ staining was performed to determine the prevalence of apoptotic cells following treatment with different concentrations of pancratistatin. There were $6.5 \%$, $9.9 \%, 15.0 \%$, and $24.2 \%$ of apoptotic HCT-15 cells at pancratistatin concentrations of $0,7.5,15$, and $30 \mu \mathrm{M}$, respectively (Figure 3). Western blot showed that pancratistatin treatment of HCT-15 cells was associated with increased expression of Bax and reduction of $\mathrm{Bcl}-2$ expression, supporting the effects of apoptosis in HCT-15 cells (Figure 4). 
A

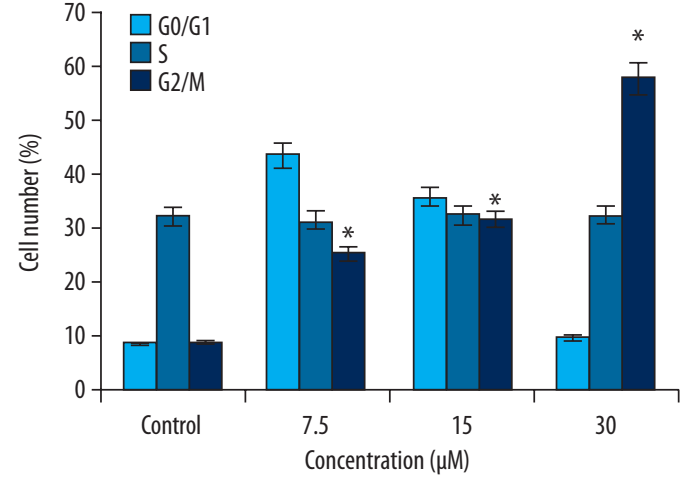

B

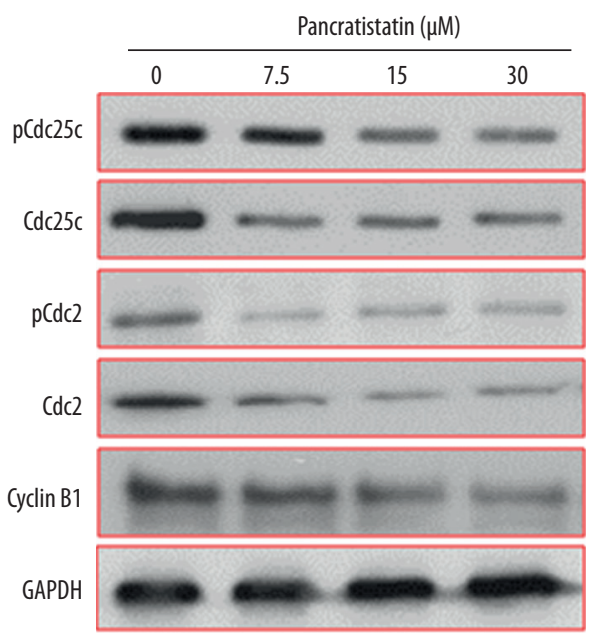

Figure 7. The effects of pancratistatin on the cell cycle and expression of cell cycle-associated proteins in colorectal cancer cells in vitro. (A) Histogram showing the distribution of the HCT-15 cells in different phases of the cell cycle at indicated concentrations of pancratistatin. (B) Western blot shows that pancratistatin is associated with a dose-dependent decrease in the expression of the cell cycle-associated proteins. The experiments were performed in triplicate and expressed as the mean \pm standard deviation (SD) ( ${ }^{*}<<0.05$ for the treated cells compared with the untreated cells).

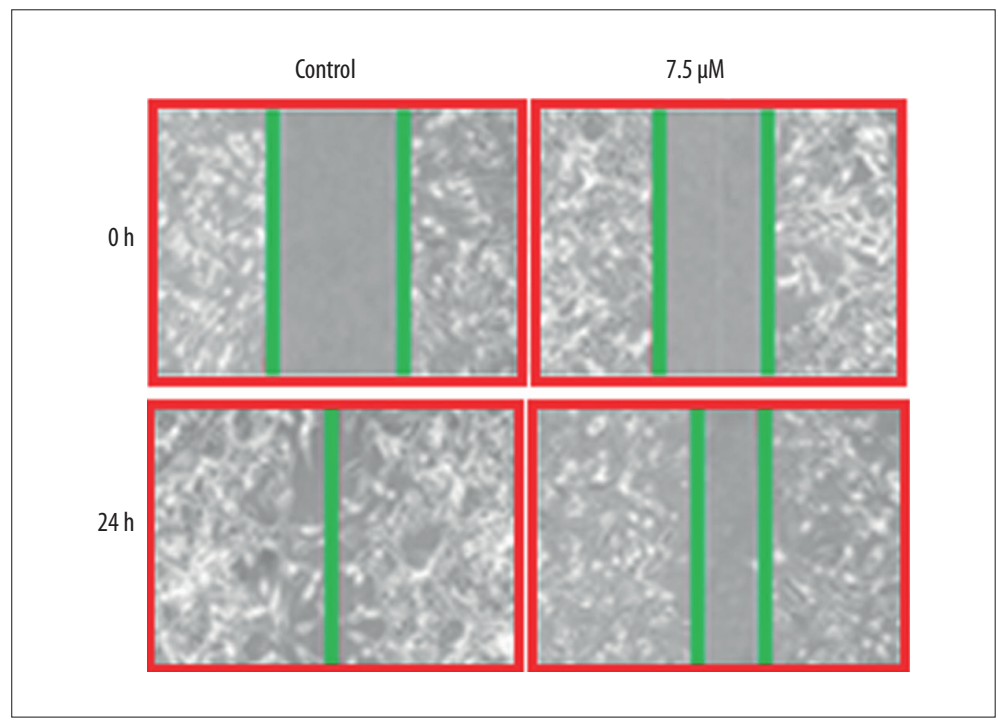

Figure 8. Wound healing assay shows the effects of pancratistatin on the migration of the HCT-15 colorectal cancer cells at $\mathrm{IC}_{50}$. The experiments were performed in triplicate.

\section{Autophagy induced by pancratistatin on the HCT-15 colorectal cancer cells}

Electron microscopy of the pancratistatin-treated HCT-15 cells showed the development of autophagic vesicles or autophagosomes, which are the morphological hallmarks of autophagy (Figure 5). Also, pancratistatin treatment resulted in increased protein expression levels of LC3B-II, ATG-5, and ATG-12, and beclin-1. However, no effects were observed on the protein expression level of LC3B-I (Figure 6).

\section{Pancratistatin resulted in G2/M cell cycle arrest of colorectal cancer cells}

HCT-15 colorectal cancer cells were treated with increasing concentrations of pancratistatin, and the distribution of HCT-15 cells at each phase of the cell cycle was determined by flow cytometry, which showed that cells in the G2/M phase increased significantly. The percentage of cells in the G2/M phase were $9 \%, 25.5 \%, 31.7 \%$, and $58 \%$ at concentrations of $0,7.5,15$, and $30 \mu \mathrm{M}$ of pancratistatin, indicating $\mathrm{G} 2 / \mathrm{M}$ arrest of the HCT-15 cells (Figure 7A). Western blot analysis showed that phosphorylation of $\mathrm{Cdc} 2$ and $\mathrm{Cdc} 25 \mathrm{c}$ was inhibited in 
a concentration-dependent manner together with decreased expression of total Cdc2, Cdc25c and cyclin B1 (Figure 7B).

\section{Pancratistatin treatment inhibited the migration of colorectal cancer cells}

The effects pancratistatin of cell migration of HCT-15 colorectal cancer cells was assessed by the wound healing assay. The results showed that the treatment of HCT-15 cells with pancratistatin for $24 \mathrm{~h}$ reduced cell migration, which was measured as the wound width (Figure 8).

\section{Discussion}

Colorectal cancer is associated with high mortality rates and its incidence is expected to increase significantly in the next few decades [11]. Unsatisfactory clinical outcome, treatments that lack efficacy and that are associated with adverse effects remain as major hurdles in the treatment of colorectal cancer. Also, the emergence of chemoresistance and frequent recurrence of colorectal cancer makes it more difficult to treat $[2,3]$. The findings of the present study showed that pancratistatin, an important component of the herbal medicine compound derived from the family amaryllidaceae, exerted growth inhibitory effects on human colorectal cancer cells in a dosedependent manner.

The findings of the present study are supported by findings from previously published studies that showed that pancratistatin treatment inhibited the growth of the colon cancer cells [12]. In the present study, pancratistatin was shown to have limited cytotoxicity for normal CDD-18Co human colonic fibroblasts, indicating that pancratistatin acted specifically on the malignant colorectal cancer cells. Pancratistatin also caused morphological changes in the HCT-15 cells which were characteristic of apoptosis using DAPI and Annexin-V staining. The effects of pancratistatin on apoptosis of HCT-15 colorectal cancer cells was supported by the finding that Bax expression was increased

\section{References:}

1. Siegel R, DeSantis C, Jemal A: Colorectal cancer statistics, 2014. Cancer J Clin, 2014; 64(2): 104-17

2. Arnold $M$, Sierra $M S$, Laversanne $M$ et al: Global patterns and trends in colorectal cancer incidence and mortality. Gut, 2016: 2: 2-7

3. Guinney J, Dienstmann R, Wang $X$ et al: The consensus molecular subtypes of colorectal cancer. Nat Med, 2015; 21(11): 1350-56

4. Van Cutsem E, Cervantes A, Adam R et al: ESMO consensus guidelines for the management of patients with metastatic colorectal cancer. Ann Oncol, 2016; 27(8): 1386-22

5. Newman DJ, Cragg GM: Natural products as sources of new drugs from 1981 to 2014. J Nat Prod, 2016; 79(3): 629-61

6. Patridge E, Gareiss P, Kinch MS, Hoyer D: An analysis of FDA-approved drugs: Natural products and their derivatives. Drug Discov Today, 2016; 21(2): 204-7 and $\mathrm{Bcl}-2$ expression was decreased. Previous studies have also shown the ability of pancratistatin to induce apoptosis, as shown by inhibition of the growth of rat and human cancer cells [13]. Pancratistatin has been shown to induce both apoptosis and autophagy in prostate cancer cells [14]. Therefore, in the present study, electron microscopy was performed to examine the pancratistatin-treated HCT-15 colorectal cells, which showed that pancratistatin caused the formation of autophagic vacuoles. Autophagy induced by pancratistatin was confirmed by Western blot, which showed increased expression of LC3II and beclin-1. Autophagy is a degradation process that eliminates defective proteins and organelles and plays an important role in inhibition of tumorigenisis [15].

The effects of pancratistatin and the distribution of the HCT-15 cells in different phases of the cell cycle were examined and showed an increase in cells in the G2/M phase in a concentration-dependent manner. Cell cycle arrest is one of the main mechanisms by which many anticancer agents halt the growth of cancer cells, and previous studies have also shown the potential of pancratistatin to cause cell cycle arrest of the cancer cells [16]. Pancratistatin has also been shown to inhibit the metastasis of different cancers [17]. Therefore, the effects of pancratistatin were also examined on the migration of the HCT-15 cells, which showed that pancratistatin treatment resulted in significantly reduced cell migration of HCT-15 colorectal cancer cells.

\section{Conclusions}

This study aimed to investigate the effects of pancratistatin in human colorectal cancer cells in vitro. The findings showed that pancratistatin inhibited the growth of colorectal cancer cells by inducing apoptosis, autophagy, and G2/M cell cycle arrest.

\section{Conflict of interest}

None.

7. Harvey AL, Edrada-Ebel R, Quinn RJ: The re-emergence of natural products for drug discovery in the genomics era. Nat Rev Drug Discov, 2015; 14(2): 111-29

8. Rinner U, Hudlicky T, Gordon H, Pettit GR: A $\beta$-carboline-1-one mimic of the anticancer amaryllidaceae constituent pancratistatin: Synthesis and biological evaluation. Angew Chem Int Ed Engl, 2004; 116(40): 5456-60

9. Pettit GR, Gaddamidi V, Cragg GM et al: Isolation and structure of pancratistatin. Journal of the Chemical Society, Chemical Communications, 1984; 24: 1693-94

10. Kekre N, Griffin C, McNulty J, Pandey S: Pancratistatin causes early activation of caspase- 3 and the flipping of phosphatidyl serine followed by rapid apoptosis specifically in human lymphoma cells. Cancer Chemother Pharmacol, 2005; 56(1): 29-38 
11. Aran V, Victorino AP, Thuler LC, Ferreira CG: Colorectal cancer: Epidemiology, disease mechanisms and interventions to reduce onset and mortality. Clin Colorectal Cancer, 2016; 15(3): 195-203

12. Griffin C, Karnik A, McNulty J, Pandey S: Pancratistatin selectively targets cancer cell mitochondria and reduces growth of human colon tumor xenografts. Mol Cancer Ther, 2011; 10(1): 57-68

13. Pandey S, Kekre N, Naderi J, McNulty J: Induction of apoptotic cell death specifically in rat and human cancer cells by pancratistatin. Artif Cells Blood Substit Immobil Biotechnol, 2005; 33(3): 279-95
14. Griffin C, McNulty JA, Pandey S: Pancratistatin induces apoptosis and autophagy in metastatic prostate cancer cells. Int J Oncol, 2011; 38(6): 1549-56

15. Kondo Y, Kanzawa T, Sawaya R, Kondo S: The role of autophagy in cancer development and response to therapy. Nature Rev Cancer, 2005; 5(9): 726-34

16. Mutsuga M, Kojima K, Yamashita M et al: Inhibition of cell cycle progression through specific phase by pancratistatin derivatives. Biol Pharm Bull, 2002; 25(2): 223-28

17. McLachlan A, Kekre N, McNulty J, Pandey S: Pancratistatin: A natural anticancer compound that targets mitochondria specifically in cancer cells to induce apoptosis. Apoptosis, 2005; 10(3): 619-30 